\title{
A PSICANÁLISE SOB O RISCO DA DEMÊNCIA
}

\author{
André Quaderi* \\ Tradução de: Bianca Novaes
}

\section{RESUMO}

Nossa pesquisa começa por uma "aposta pascaliana" sobre a existência de um sujeito na demência, existência negada na maioria dos trabalhos sobre a demência ou pelo menos bastante explícita clinicamente. A análise dos trabalhos sobre as perturbações da linguagem demonstra uma recusa em reconhecer as possibilidades de comunicação e de relação com os dementes. As pesquisas reduzem as dimensões pragmáticas do discurso de Austin e as análises do sujeito da enunciação de Benveniste e de Bakhtin, provocando uma destituição do demente do campo da fala. Nós propomos uma nova análise do paciente demente, sublinhando sua existência na fala. Através de um diário clínico que cartografa diferentes modos de abordagem dos dementes, propomos um método de trabalho com esse tipo de paciente. Nós analisamos algumas produçôes, certamente reduzidas, dos dementes como autênticas formações do inconsciente, tal como as concebem Freud e Lacan. Nossa proposta articula-se em torno das abordagens clínicas de Ferenczi e Winnicott, apresenta técnicas relacionais a partir de um cuidado materno e de um fluxo de compaixão. Uma ética vem à luz, tomada do referencial analítico.

Palavras-chaves: demência; psicanálise; psicopatologia; sujeito; fala; inconsciente.

\section{Abstract}

\section{PSYCHOANALYSIS UNDER THE RISK OF DEMENTIA}

Our research starts with a type of "Pascal's bet": the existence of a subject inhabited by speech within dementia. Analysis of various works on speech defects shows a lack of knowledge regarding the communication possibilities of these individuals. Research leaves out Austin's pragmatic dimensions, Benveniste's overhangs and Bakthin's analysis, and therefore dismisses the demented person from the field of speech. We offer a new analysis of the demented patient which underlines his existence within the speech area. Helped by Freud and Lacan's unconscious

* Mestre de Conferências em Psicopatologia Clínica (Université de Provence). 
development and by a clinical diary (which will "map-make" the various caring approaches of the demented person) we offer a clinical method. Developed around Ferenczi and Winnicott's clinical perspectives our work presents relationship techniques based upon mothering-type care and compassionate flow. An ethical path then appears, not opposed to an analytical referential.

Keywords: dementia; psychoanalysis; psychopathology; subject; speech; unconscious.

\section{A APOSTA NO SUJEITO DA DEMÊNCIA}

A psicanálise desenvolve, há mais de 100 anos, um método de cuidado psíquico. Os novos horizontes desde Freud são múltiplos. Muitos psicanalistas se aventuraram além da relação clássica divã-poltrona. Entretanto, zonas inteiras do psiquismo permanecem desconhecidas. O psicanalista sem divã, como dizia tão justamente Paul-Claude Racamier (1970), é um "personagem que, no contexto institucional onde se situa o cuidado de pacientes em grande dificuldade psíquica, se põe a transpor metodicamente o que ele compreende graças ao conhecimento psicanalítico e ao que ele intimamente reteve da experiência da psicanálise" (Racamier, 1970: 5). Numerosos, com efeito, são os pacientes que sofrem psiquicamente e que, entretanto, escapam aos recursos próprios à situação psicanalítica. É uma espécie de aventura para um psicanalista e um modo de se extrair da situação propriamente psicanalítica. Para libertar-se do método, aventurar-se nas zonas onde os conceitos vêm à luz à medida do avanço clínico, são necessários audácia e rigor. Em situação de sofrimento psíquico extremo, é então importante falar de algo além da teoria de pacientes, de pessoas. Sem divã, para retomar a metáfora de Racamier (1970), e fora de nossas poltronas, fomos ao encontro de pacientes acometidos pela doença de Alzheimer e por patologias semelhantes.

O trabalho com pacientes acometidos por patologias neurovegetativas como a demência de tipo Alzheimer necessita de uma reordenação dos conceitos e dos métodos de trabalho, levando o psicólogo clínico aos extremos da relação humana. Evidentemente, um a priori se impõe a todo clínico: a aposta na presença de uma vida psíquica no demente (Messy, 1992). Esse postulado se apresenta como um elemento fundamental daquilo que pode promover uma interlocução entre o demente e o clínico.

Um sentimento misturando pavor e solidão toma conta de todo terapeuta em um novo campo clínico. Sem referencial teórico (e, então, sem identidade no sentido de Fedida, 1992), o deserto metodológico ${ }^{1}$ se abre diante do psicanalista. No nível metapsicológico, e sempre no campo do envelhecimento, o paradigma estrutural na lógica lacaniana foi desenvolvido por Jacques Messy (1992). Segun- 
do ele, o processo de envelhecimento induz um estágio de espelho invertido. A ferida narcísica do ideal do eu provoca a criação de um "eu feio" (moi hideur). Assim, ressurge de maneira prevalecente no envelhecimento o Hilflosigkeit (a perda da ajuda, do apoio sobre o objeto de amor primário) (Assoun, 2003). As fundações psíquicas são assim abaladas pelos golpes de perdas. Parece-nos importante sublinhar que suas teorias não conduzem à elaboração de uma prática clínica coerente. Saudamos, todavia, aqui, o notável trabalho de Jean-Marc Talpin (2005) no livro coletivo Cinq paradigmes cliniques du vieillissement [Cinco paradigmas clínicos do envelhecimento], que tenta elaborar um laço entre metapsicologia e método clínico na velhice. Nosso projeto aqui desdobrado vai dedicar-se a desenvolver uma abordagem clínica original da pessoa acometida pela doença de Alzheimer e por doenças semelhantes a um estado grave. É então um prolongamento desse trabalho que tentaremos aqui.

Nenhuma orientação há, na abordagem desses pacientes, nas produções teóricas essencialmente calcadas sobre um aspecto metapsicológico. A aposta pascaliana desempenha já um primeiro lance, criando uma possível exploração de um novo campo praxeológico da psicanálise. É, então, a uma heurística em curso que essa aposta louca conduz. Segundo Aulagnier (1975), duas possibilidades se oferecem aos praticantes diante de um novo campo. A primeira consiste em nada mudar o modelo analítico que dá conta dessa relação com a pessoa (aqui, o demente). A segunda leva a reconhecer o que, no nível da demência, o modelo analítico deixa fora de campo, reconsiderando as noçôes de "sujeito" ( $j e)$ e a função do discurso.

\section{DEFINIÇÃO DA DEMÊNCIA}

A Organização Mundial de Saúde dá como definição (quase idêntica àquela do $D S M-I V)$ da demência:

Alteração progressiva da memória e da ideação suficientemente marcada por prejuízo, desde ao menos seis meses, e perturbação de pelo menos uma das funções seguintes: cálculo, juízo, alteração do pensamento abstrato, praxias, gnosias ou modificação da personalidade (Hazif-Thomas, Hazif-Thomas \& Arroyo-Anllo, 1999: 74).

O recurso previamente enunciado na aposta pascaliana impóe-se diante de tantas patologias que acometem o sujeito. $\mathrm{O}$ sujeito demente não se reconhece mais nele nem em seus próximos, verdadeiro morto-vivo para os seus, que vêm nele, ao mesmo tempo, um ser amado e um "outro" estranho ${ }^{2}$. O demente ignora 
que é demente e, devido às perturbações da memória, ele próprio esquece suas perturbações. Ele só fala raramente, acometido por afasia e agnosia. Para entrar verdadeiramente em relação com ele, o clínico é então constrangido, por sua transferência, a crer no caráter humano da demência, pois lhe parece impossível crer em outra coisa. Essa crença se coloca por obrigação moral, induzindo logicamente a considerar a palavra do demente como elemento de verdade. Fala-ser (parlêtre) não falando quase nada, o demente representa uma fronteira, aquela da compreensão do humano e da teoria analítica.

\section{O SUJEITO ANALÍTICO}

A definição analítica de um sujeito para Lacan é impossível de isolar da linguagem e de sua estrutura, remetendo ao uso do significante. Esse último assim se define, segundo Lacan: "nossa definição do significante (não existe outra) é: um significante é aquilo que representa o sujeito para outro significante” (Lacan, [1960] 1966: 819).

Lacan introduz, então, um laço entre o sujeito, o inconsciente e o significante. Ele afirma:

Mas a novidade da análise, [...] é justamente isto, que alguma coisa pode se sustentar na lei do significante, não apenas sem que esta comporte um saber, mas dela o excluindo expressamente, dela se constituindo como inconsciente, ou seja, como necessitando em seu nível do eclipse do sujeito para subsistir como cadeia inconsciente, como constituindo o que há de irredutível, no fundo da relação do sujeito ao significante (Lacan, [1959-1960] 1986: 143).

Como então falar de sujeito na demência no sentido analítico do termo, um sujeito do inconsciente?

Lacan, seguindo Freud, vai utilizar, para delimitar o sujeito, a construção da palavra "familionário" como uma "condensação acompanhada da formação de um substituto", significando a vida psíquica inconsciente. Freud, e Lacan ([19571958] 1998) o retoma tal qual em seu seminário sobre as formações do inconsciente, propóe o esquema seguinte:

famili ar

mili onário

faMILIonÁRIO 
Essa figuração determina os mecanismos de condensação e de transformação, exprimindo um sentido que escapa à consciência. O "familionário" é, então, o testemunho de uma vida psíquica. Por ocasião de numerosos encontros, participei, com a condição de abrir e sustentar a demanda na entrevista com o demente, do aparecimento de uma condensação similar, sinal da continuidade de uma vida psíquica na demência. Por exemplo, uma paciente no curso de uma entrevista verbaliza: "eu sou uma velha soeurcière $e^{3}$, eu tenho coisas horríveis em minha cabeça”. Para mim, esse surgimento assinala a presença de mecanismos idênticos ao "familionário", permitindo sublinhar a presença no curso de uma entrevista de uma vida psíquica, aqui inconsciente, no sentido de Lacan, no demente.

Isso conduz, legitimamente, a reproduzir o esquema de Freud:

So(eu) $r$

Sor (ci) ère

SoeRcièRE

Uma outra paciente, no curso de uma entrevista, me dirá: "eu sou pleureuse $e^{4}$, querendo exprimir "eu não sou mais heureuse", o que pode ser significado da maneira seguinte:

je ne suis plus heureuse [eu não sou mais feliz] pleureuse [chorosa]

JE SUIS PL EUREUSE [eu sou chorosa]

Essa elisão da negação [ne] e do fonema "us" [de plus] sublinha a performance do dizer em um ato que, ao mesmo tempo, significa a ausência de felicidade e as lágrimas correlatas. Verdadeiras construções do inconsciente, esses dois neologismos tornaram para mim a fala do demente mais clara. A operação de sentido nasce de minha interpretação e, então, de uma transferência inaugural. Totalmente siderado por essas produções dos pacientes, me percebi como aquele que faz emergir sujeito e, nesse sentido, talvez um outro, tesouro de significantes? A questão permanece em suspenso, mas sublinho que o sujeito na demência depende irrevogavelmente do outro para sustentar seus enunciados, e de um Outro para produzir significantes existenciais. A idéia pascaliana de aposta inicial, ato fundador de encontro, torna-se pouco a pouco um ato relacional específico de uma inesperada estranheza. 


\section{DiÁRIO CLÍNICO}

A partir dessa etapa essencial, um diário se desenvolve para cartografar o campo clínico que se descobre. Dou testemunho, assim, em filiação direta ao diário clínico de Ferenczi, da experimentação de uma nova abordagem dessas pessoas. O diário clínico enumera mais de 30 situações diferentes, das quais não é possível restituir aqui o conjunto. Para ilustrar essa zona do campo particularmente cruel do sentimento de nada presente na abordagem da demência, apresento um exemplo de meus primeiros desgostos. Essa entrevista ocorre no início de meu trabalho, antes de qualquer elaboração da aposta pascaliana.

Clinico: Bom dia, Senhora, como vai?

Sra. Forge: Bem, muito bem.

Clínico: Onde você está aqui?

Sra. Forge: Onde eu moro, em St. Eugène, é lá que eu moro. Você conhece?

Clínico: Não.

Sra. Forge: Ah, mas é bom, é como St. Eugène, há uma igreja, casas... Eu vou com os meus pequenos (a meia-voz: St. Eugène é em St. Eugène que eu moro). Clínico: Como se chamam seus pequenos?

Sra. Forge: Tem uma que é uma mocinha, de 13 anos, um de 12 anos. Eu os levo ao mar. Em St. Eugène há um mar, uma praia muito bonita, grande, e as crianças brincam na praia. E, depois, eu tenho Frédérique.

Clínico: Ela mora onde?

Sra. Forge: Colmar, você conhece?

Clínico: Não. Aqui você está na Casa de Retiro.

Sra. Forge: St. Eugène, é em St. Eugène que eu moro, minha filha vem me buscar...

Essa entrevista foi uma das mais dolorosas, eu me senti inútil e desarmado diante da demência. Minhas intervenções eram desajeitadas, desadaptadas, deslocadas, eu sentia uma compaixão que eu fazia calar. Esse limite que eu me impunha era para mim diretamente determinado pela técnica de não-intervenção, dessa neutralidade própria ao clínico. Searles (1981) analisa essa anestesia de sentimentos da maneira seguinte:

Funcionar segundo esse espírito de abnegação - a norma para os médicos de outras especialidades - representa aqui, na prática da psicoterapia e da psicanálise, uma defesa inconsciente do terapeuta que lhe evita claramente muitos aspectos essenciais dele mesmo e do paciente (Searles, 1981: 399). 
Se não coloco em causa essa asserção - todo clínico pôde verificar sua operacionalidade nas curas clássicas -, uma questão brota: é possível o encontro com o demente fora de um investimento diferente do clínico? Como explicar, então, esse sentimento de abatimento que me oprimiu muito tempo após essa entrevista? Pode-se mesmo falar de entrevista diante daquilo que parece ser um automatismo mental? Era de minhas intervenções carecendo de compaixão, de sinceridade, que eu me sentia culpado. Raramente me senti tão à margem do problema, sem laço com a paciente, nem mesmo um laço linguageiro. Eu não compreendia nada, estava desesperado, melhor, não me compreendia em minha identidade. Nessa entrevista, estou num rio e o paciente num outro e nada permite nos encontrar, pior ainda, a técnica, em lugar de facilitar a expressão, me impedia de agir segundo meu impulso. Desses efeitos (contra) transferenciais, a partir dessa ancoragem, o que eu podia fazer?

Eu me obstinei, entretanto, obstinação diretamente induzida pela aposta pascaliana, mas também por essa dívida contraída cuja reparação tentei fazer no início desse trabalho. Um clínico, referindo-se à psicanálise, não pode se furtar à escuta e muito menos às palavras do paciente, inclusive do demente.

De uma clínica impossível às variáveis infinitas do possível o passo semântico é simples, mas me demandou anos de esforços, principalmente para desaprender uma práxis analítica de neutralidade. Nisso, a definição do instante de dizer, segundo Del Volgo (1997), que delimita o encontro clínico reduzido a uma ou algumas entrevistas "em um instante de breve encontro" (Del Volgo, 1997: 27), me parece eficiente. Diferentemente das situaçôes descritas em seu livro, minha prática se define a partir desses breves encontros que a memória deficiente do demente reconduz como estranhamente nova.

\section{Os FUNDAMENTOS DA CLÍNICA ANALÍTICA DA DEMÊNCIA}

O próprio da clínica analítica da demência seria abordá-la fora de todo saber (semiológico e outros). Assim como o neurótico, o demente seria colocado em um a priori (Lacan emprega as palavras "idéias pré-concebidas") do desejo. O demente encontra, então, um lugar de sujeito no discurso do Outro. A modalidade metodológica modifica-se por causa dessa articulação subjetiva, lembrando a aposta pascaliana. Essa última, ato ético e fundamental, torna-se, como vimos, preliminar indispensável às entrevistas e motor do processo de subjetivação da relação. A praxeologia da demência se constrói assim.

O conjunto não é sem conseqüências técnicas e nem deixa de colocar novos problemas. Certamente, isso pode funcionar, mas sob condição, aquela do "saber 
louco" do clínico que sabe o que é bom para o paciente demente. Esse último estando na incapacidade de nomear seu desejo, de aí se reconhecer, é o clínico, propondo uma, ou para ser mais preciso, várias possibilidades de nominaçôes, que lhe permite então apreendê-lo. O desejo será aqui compreendido como deixar advir um discurso no qual o demente possa se reconhecer, tomá-lo como dele mesmo.

$\mathrm{O}$ alcance de Eros, ainda que escape, não se faz segundo a decisão do clínico e muito menos por um dispositivo técnico, mas pela posição intrapessoal, que Lacan nomeia desejo do analista. Este último permite deixar desenvolver a transferência através do sujeito desejante. Esse dispositivo visa à análise daquilo que é buscado nessas entrevistas com o demente, a saber, questionar o desejo do clínico em sua aposta pascaliana. Nosso propósito, agora que chegamos a esse estágio do percurso, será identificar o que é operacional na clínica do demente.

O que ocorre no desejo do analista diferencia-se de um objetivo de cura, mas não se separa de uma relação transferencial e, por isso mesmo, situa-se no interior de um dispositivo praxeológico. A terminologia "desejo" no "desejo do analista" não permite dispensar totalmente a intersubjetividade, mas, ao contrário, permite mostrar que esse desejo faz funcionar um discurso no qual um sujeito, e não um objeto, pode advir. A partir desse ponto preciso, parece possível afirmar que o que faz funcionar a interlocução com o demente provém dessa aposta louca, aposta pascaliana que cria, no momento mesmo em que se enuncia, o sujeito. Nossa convicção agora se desenvolve em torno da aposta pascaliana como uma autêntica regra praxeológica na clínica da demência. Em outras palavras, a aposta pascaliana funciona identicamente ao processo da regra fundamental da clínica do neurótico. Essa aposta ética aparece como uma autêntica e primeira regra da clínica do demente, lugar de nascimento de um desejo do clínico no sentido de Lacan, mas intrincado à patologia demencial das perturbaçóes dos enunciados.

\section{WINNICOTT, HOLDING, COMPAIXÃO}

Winnicott ([1952] 1969) não hesitou em trabalhar com pacientes difíceis em uma clínica densa e rude. É o testemunho de uma de suas analisantes que mostra a generosidade, a riqueza e a extrema engenhosidade desse clínico e sobretudo a similaridade de sua prática com a de Ferenczi. Em "Um témoignage" ["Um testemunho"], uma analista inglesa, Margaret Little (1986), narra sua experiência analítica com o Doutor W. Por exemplo, diante do terror, pânico e das angústias de sua paciente, Winnicott passará horas a lhe segurar a mão, interpretará os medos como um novo nascimento, velará por suas férias para 
evitar riscos suicidas (prática não muito afastada da disponibilidade de Lacan, que dava um número de telefone para ser contactável - Roudinesco, 1993), a hospitalizará e irá visitá-la regularmente. Little articula a prática de seu analista em torno dos trabalhos sobre o holding tomado "metafórica e literalmente" (Little, 1986: 466), mantendo a situação clínica em suas mãos e segurando as mãos de sua paciente. Sempre segundo Little, Winnicott, no nível de apoio, assumia toda a responsabilidade para dar ao paciente a força do eu que esse último não podia encontrar nele mesmo. Mais tarde, Winnicott deixava entrever a sua paciente o que a análise "exigia dele"... "ele devia suportar a angústia, a culpa, a dor e o sofrimento, a incerteza e a fraqueza, a impotência, ele devia suportar o insuportável” (Little, 1986: 488). A convergência com Ferenczi é aqui incontestável em sua percepção da compaixão e da simpatia que cura. Winnicott, que Little ilustra em sua relação de "maternagem" (Little, 1986: 484), simbolizaria o clínico que Ferenczi esperava ver advir? Como o húngaro, Winnicott ${ }^{6}$ ia à casa de sua paciente quando esta estava muito doente. Assistimos, na leitura dessa narrativa, à criação de uma praxeologia de um clínico que inventa a análise com sua paciente. Não devemos deixá-lo nos guiar sobre essa via certamente angustiante, na qual a técnica faz corpo com o clínico, como Gori e Hoffman (1999) o entendem, no sentido do método?

\section{Clínica da demênCia E Hilflosigkeit}

Eis agora um exemplo clínico no qual, finalmente desembaraçado de minhas roupagens técnicas habituais, eu me entregava às conseqüências de minha aposta pascaliana. Nessa entrevista, estava presente uma jovem estagiária psicóloga. Sra. Porte está sozinha, deitada ao longo de sua poltrona, as mãos sobre sua cabeça, mergulhadas em seus cabelos. Quando entramos, ela não reage, só mostrará o rosto quando nos aproximamos dela o suficiente para que ela sinta nossa presença através de nossa voz.

Clínico: Bom dia, Sra. Porte, como vai você hoje?

Sra. Porte: Bom dia, Senhor.

Eu lhe aperto a mão (eu aponto e faço-a estender a mão à estagiária)

Sra. Porte: Bom dia, Senhora. Oh! você tem as mãos frias, isso vai me aquecer. A paciente está com o nariz escorrendo, pego um lenço e lhe assôo o nariz. Aproveito para the tomar as mãos e lhe acariciar o rosto. Eu lhe estendo também um lenço. Tudo isso lhe falando pelos gestos que executo.

Sra. Porte: Oh! muito obrigada por isso, vou colocá-lo em minha bolsa. 
Ela hesita, eu a guio para colocar o pacote em sua bolsa. Eu lhe tomo a mão, a coloco sobre minha face e lhe falo de maneira suave, mas com forte intensidade, lhe perguntando como ela vai.

Sra.Porte: Eu aí não vejo, eu não vejo nada aí desde ontem, uma semana... Oh! eu estou farta, eu sou uma velha carroça.

Clínico: Eu lhe digo rindo: e quem puxa a carroça?

Sra.Porte: Oh! se algo puxa não sou eu, é a juventude, que está aí como vocês, aí (aponta a estagiária) e aí (me aponta).

Nesse momento, ela toma as mãos da estagiária e diz:

Sra. Porte: A juventude tem as mãos frias... Então o trabalho como vai?

A estagiária e eu mesmo respondemos: Sim, vai tudo bem.

Sra.Porte: É importante isso para que o trabalho vá bem.

Ela me mostra sua boca para comer.

Sra.Porte: Oh! e depois não é bom, eu tenho dor nos olhos, eu quero partir faz dois anos que eu estou lá, eu quero partir. Oh! estou farta de mim, eu quero partir os pés na frente (ela imita, fazendo o gesto de pés na frente).

Clínico: É o quê? Eu não compreendo.

Sra. Porte: É o círculo onde você coloca os pés na frente e a cabeça atrás (ela imita com suas mãos) eu creio que é possível colocar a cabeça também na frente enfim eu não sei. Eu não vejo aí, eu tomei café da manhã lá, café com leite, café. Trocaram as camas, mas não trocaram os lençóis. Ela aponta sua cama.

Massageei a paciente, pois ela começava a repetir de maneira idêntica sua fala. Ela recusa sempre, no início, a massagem e a aceita no fim. Ela me agradece agora no final da entrevista, várias vezes, e me pede para voltar, o que é totalmente novo.

Seu "agradeço por sua visita, isso faz passar o tempo", seu pedido de que nós voltemos me questionam. Inútil pensar essa expressão como uma simples forma de polidez. O que é endereçado ao clínico deve ser compreendido, desde Ferenczi, através do quadro transferencial. Essa mulher me ensina o alvo de minha visita, me agradecendo, ela admite que houve um antes e um depois. Levando em consideração o que se sabe da demência e de sua percepção desorientada, o agradecimento da visita tem um efeito transferencial sobre mim. Enfim, o uso da metáfora "os pés na frente" testemunha a meus olhos o fala-ser (parlêtre) existente apesar da demência. O sujeito persiste com a condição da assinatura do Outro.

O projeto é então produzir efeitos de fala pela posição subjetiva do clínico (maternal, desejante fundado sobre uma dinâmica de amor). No artigo "Psicose e cuidados maternos", Winnicott ([1952] 1969) articula ao estado de dependência 
da criança, de aflições primitivas tais como Freud poderia defini-las com o conceito de Hilflosigkeit, o papel da mãe, não nos gestos precisos, mas no ambiente que compensa essa aflição. Essa abordagem parece complementar ao percurso técnico de Ferenczi em sua pesquisa sobre o cuidado materno, que ele opõe à frieza da posição do analista clássico. $\mathrm{O}$ cuidado materno não está exclusivamente no gesto técnico de alívio (relaxamento, gestos afetuosos, dar de comer, etc.) de nossa clínica (idêntica nisso àquela de Ferenczi). O cuidado materno está também e pode estar sobretudo na criação de um ambiente de linguagem.

\section{O AMBIENTE SIGNIFICANTE: UM CUIDADO MATERNO}

É Jacques Hochmann (1994) com sua coletânea La Consolation que me leva a reconsiderar o ambiente para uma abordagem da demência de outra maneira que apenas sob o aspecto da arquitetura e das estimulaçōes cognitivas. Os estudos sobre a abordagem da demência falam de arquiteturas "proféticas", ou seja, portadoras de intenção, mas omitindo um ponto essencial: o ambiente significante, a instituição mental para retomar a denominação de Hochmann.

A proposta, para torná-la mais clara, é, então, uma nova abordagem da demência, certamente dual, na discursividade, mas também potencialmente estendida a outros atores dos cuidados de uma Casa de Retiro "clássica" e, seguramente, das unidades de Alzheimer. A equipe poderia criar um ambiente verbal, permitindo ao demente viver e existir no discurso de significantes ambientais. A proposta não se limita de forma alguma a uma sistematização autoritária, mas antes a um ambiente tal como Hochmann define para as crianças autistas através do conceito de alívio.

\section{Conclusão}

Se a psicanálise não for portadora desse discurso metonímico e metafórico para a demência, então ninguém o fará, nisso reside sua responsabilidade.

A psicanálise baseia sua teoria sobre a linguagem e seus avatares metonímicos e metafóricos, induzindo principalmente as formações do inconsciente, o fantasma e a castração. Todo praticante é, então, logicamente conduzido a se propor como um clínico produtor de metáfora e metonímia, esperando delas produzir efeitos de fala.

Essa hermenêutica considera o demente em perpétuo estado de demanda, complexa e dificilmente inteligível, demanda não de cuidado, mas demanda a ser no outro. Existir de outra maneira que não por cuidados veterinários, existir no 
desejo do outro, o tempo da vírgula da palavra, espaço pusilânime se nele está, mas do qual por vezes se alimenta.

Não conhecer minha própria humanidade senão reconhecendo aquela de meu irmão demente, eu marco a ação de um desejo e seus alvos inconscientes, produzindo minimamente um novo espaço para viver, frágil e parcial, reduzido a esses instantes de falas, ato fundador de existência.

Escutar os dementes e suas crises existenciais na imediatidade de seu vivido, certamente suposto para nós (a prova faz falta), é um ato ético no sentido analítico do termo: não derrogo do lugar que ocupo, aquele da e endividação perpétua do clínico (no sentido de Aulagnier, 1975) diante de seu paciente que ignora o como da relação. A aposta pascaliana então evoluiu bem desde o início desse longo trabalho clínico. Da simples hipótese fundada sobre uma noção moral, sua pertinência tanto no nível da gramática quanto do sujeito do inconsciente irrompe. Essa aposta constrangeu meu corpo, proibindo de embarcar numa terra clínica totalmente fria, dura, árida, extrema, mas não desértica de conceitos. Para acabar, a aposta pascaliana encerra em si mesma, como uma ética que me ultrapassa, aquela da psicanálise, universal e insuperável. Em uma via nova, mas na qual as iniciativas se multiplicam, na qual as necessidades são imensas e as pesquisas tornam-se inumeráveis, asseguramos que o futuro está amplamente aberto, tal como termina o preâmbulo de Racamier (1970) no seu livro sobre o psicanalista sem divã. Eis-nos nesse estado na abordagem dos pacientes dementes.

\section{REFERÊNCIAS BIBLIOGRÁFICAS}

Assoun, L. (2003). Le vieillissement à l'épreuve de la psychanalyse. Em Houziaux, A. Comment accepter de vieillir? (pp. 59-96). Paris: Les éditions de l'atelier.

Aulagnier, P. (1975). La violence de l'interprétation. Paris: PUF.

Del Volgo, M-J. (1997). Linstant de dire, le mythe individuel du malade dans la médecine moderne. Paris: Erès.

Fedida, P. (1992). Crise et contre-transfert. Paris: PUF.

Gori, R. \& Hoffmann C. (1999). La science au risque de la psychanalyse. Paris: Erès.

Hazif-Thomas, C.; Hazif-Thomas, P. \& Arroyo-Anllo, E. M. (1999). Histoire du concept de démence. Gérontologie et société, 88, 49-78.

Hochmann, J. (1994). La Consolation, essai sur le soin psychique. Paris: Odile Jacob.

Lacan, J. (1957-1958). Le séminaire, Livre V, Les formations de l'inconscient. Paris: Seuil, 1998. 
(1959-1960). Le séminaire, Livre VII, L'éthique en psychanalyse. Paris: Seuil, 1986.

- (1960). Subversion du sujet et dialectique du désir dans l'inconscient freudien. Em Écrits (pp. 793-827). Paris: Seuil, 1966.

Le Gouès, G. (1991). Le psychanalyste et le vieillard. Paris: PUF.

Little, I. M. (1986). Un témoignage, en analyse avec Winnicott. Em Pontalis, J. B. (Org.). L'Amour de la haine (pp. 447). Paris: Gallimard.

Maisondieu, J. (1996). Le crépuscule de la raison, Comprendre, pour les soigner les personnes ageées dépendantes. Paris: Bayard.

Messy, J. (1992). La personnage et n'existe pas. Paris: Rivages.

Ploton, L. (1996). Maladie Alzheimer à l'écoute d'un langage. Lyon: Chronique Sociale.

Racamier, P.-C. (1970). Le psychanalyste 100 divan. Paris: Payot.

Roudinesco, E. (1993). Jacques Lacan. Paris: Fayard.

Searles, H. (1981). Le "médecin dévoué" dans la psychothérapie et la psychanalyse. Em Pontalis, J. B. (Org.). L'Amour de la haine (pp. 395). Paris: Gallimard.

Talpin, J.-M. (2005). Cinq paradigmes cliniques du vieillissement. Paris: Dunod.

Trintignant, M. (1997). Ton chapeau au vestiaire. Paris: Fayard.

Winnicott, D. W. (1947). La haine dans le contre transfert. Em De la pédiatrie à la psychanalyse (pp. 48-58). Paris: Sciences de l'homme Payot, 1969. - (1952). Psychose et soin maternels. Em De la pédiatrie à la psychanalyse. Paris:

Sciences de l'homme Payot, 1969.

\section{NoTAS}

1 Teorias explicativas da demência existem (Ploton, 1996; Maisondieu, 1996; Le Gouès, 1991), mas não há método clínico.

2 Marie Trintignant (1997) em seu livro Ton chapeau vestiaire descreve esse estado de maneira pungente. Eu não citarei dele senão algumas linhas: "Não se compreende sua estranha doença. Ela não mais, nada além disso [...] Lilou não vê o Outro, ela. Ou ainda, se esqueceu, você. Eu não sei" (Trintignant, 1997: 105).

3 N.T.: Soeurcière é a condensação da palavra soeur, que significa "irmã" com a palavra "sorcière", que significa "feiticeira".

4 N.T.: Pleurese diz-se de alguém que está prestes a chorar ou que acaba de chorar, algo como "chorosa".

5 N.T.: Heureuse significa "feliz".

6 Winnicott ([1947] 1969) dá testemunho desse tipo de prática em um outro artigo sobre o ódio. 
7 N.T.: A paciente imita o gesto de colocar os pés na frente, mas ao se expressar verbalmente utiliza antes de "pés na frente" o verbo "partir", construindo uma expressão francesa (partir les pieds devant) que significa "sair de casa no caixão".

Recebido em 13 de dezembro de 2007 Aceito para publicação em 08 de maio de 2008 